\section{O desastre de Numância e a iconografia numismática: relendo dois denários cunhados em 137 AEC}

\author{
The disaster of Numantia and the numismatic iconography:
}

rereading two denarii minted in $137 \mathrm{BCE}$

\section{Gisele Oliveira Ayres Barbosa*}

Resumo: $O$ presente artigo tem como proposta analisar as imagens monetárias de dois denários cunhados em Roma no ano de 137 AEC, com o objetivo de refletir sobre a relação dessas cunhagens com o debate que ocupou grande parte da elite romana naquele ano, a respeito da ratificação ou não do tratado feito pelo general Caio Hostílio Mancino com a cidade de Numância. As peças foram emitidas pelos monetários Tibério Vetúrio e Sexto Pompeu. Representações de divindades e referências aos ancestrais e ao passado da cidade de Roma participam da elaboração do discurso numismático, revelando posições antagônicas acerca do debate em curso.

\begin{abstract}
The purpose of this article is to analyze the monetary images of two denarii minted in Rome in the year 137 BCE in order to reflect on the relation of these coinage with the debate that occupied a large part of the Roman elite that year, regarding ratification or not of the treaty made by the general Caius Hostilius Mancinus with the city of Numantia. The pieces were issued by the monetaries Tiberius Veturius and Sextus Pompeius. Representations of deities and references to the ancestors and the past of the city of Rome participate in the elaboration of the numismatic discourse, revealing opposing positions on the ongoing debate.
\end{abstract}

Palavras-chave: República romana; Imagens monetárias; Tratado de Numância; Deuses;

Ancestrais.

\section{Keywords:}

Roman Republic; Monetary images; Treaty of Numantia; Gods; Ancestors.

\footnotetext{
* Doutora em História pela Universidade Federal do Estado do Rio de Janeiro (UNIRIO) e professora do Centro Universitário Geraldo Di Biasi.
} 


\section{Introdução}

$\mathrm{N}$ a década de $130 \mathrm{AEC}$, a iconografia numismática romana passou por significativas transformações, responsáveis por imprimir nas peças um padrão inédito para o Mundo Antigo. Ao lado das referências a deuses e símbolos religiosos, frequentes nas cunhagens desde seu surgimento, alusões ao cotidiano e à vida pública dos romanos se tornaram cada vez mais constantes nas moedas. Análises pioneiras sobre o fenômeno e que ainda são utilizadas como referências em estudos relativamente recentes tentaram compreender o movimento a partir de motivações políticas, mais especificamente a mudança do sistema de votação nas assembleias romanas para eleição dos magistrados, em 139 AEC.

A passagem do voto oral e aberto para o voto escrito e secreto teria tornado necessárias novas formas de promoção junto ao eleitorado, por meio de variadas mídias, inclusive imagens monetárias (WISEMAN, 1971, p. 4-5; p. 148-149; CRAWFORD, 1974, p. 710; p. 728; SUSPÈNE, 2002, p. 42; MORSTEIN-MARX, 2004, p. 82-83; WELCH, 2006, p. 531). Posteriormente, dentro de uma perspectiva cultural mais ampla, foi sugerido que o movimento seria parte do processo de "monumentalização" da sociedade romana ocorrido na mesma época (MEADOWS; WILLIAMS, 2001, p. 40-43). Creio que essa abordagem, que não ignora os aspectos políticos que contribuíram para a mudança, mas não se restringe a eles, é, sem dúvida, mais apropriada para se refletir sobre o fenômeno.

"Monumentalizar" equivaleria a "trazer à mente", por meio de apelos principalmente visuais, tais como monumentos, inscrições, edifícios e, também, moedas. Para a competitiva aristocracia romana, demonstrações públicas de status eram de grande importância, especialmente com o intuito de relembrar a seus pares e ao povo a posição política e social da família, no passado e no presente. A palavra em latim que abarca todas essas atividades é monumentum, que claramente deriva da mesma raiz de Moneta, a deusa em cujo templo se localizava a oficina de cunhagem na Roma Republicana. Ambos, por sua vez, derivam do verbo latino moneo, que aqui deve ser tomado não no sentido de "alertar", "avisar", mas de "fazer pensar", "lembrar" (ERNOUT; MEILLET, 2001, p. 731-732). Sem abandonar o conceito das moedas romanas como "monumentos em pequena escala" (MEADOWS; WILLIAMS, 2001, p. 40-43), Anna Clark (2007, p. 139) classificou esses recém-surgidos tipos numismáticos como novos e pequenos "espaços portáteis", nos quais os monetários podiam pensar sobre si mesmos, suas famílias, sua cidade, seu passado e seu presente. ${ }^{1}$

\footnotetext{
${ }_{1}^{1}$ Aqui o termo se refere ao magistrado romano responsável pelas cunhagens. Um conjunto de três magistrados menores (tresuiri monetales) detinha a função de emitir moedas em nome da República.
} 
Nesse processo, a alusão aos ancestrais era frequente, uma vez que a aristocracia romana era uma elite cuja autoridade se fundamentava no controle do comportamento social e na evocação regular dos ancestrais como um critério de legitimação de suas ações e de autenticação de sua conduta (WALLACE-HADRILL, 2009, p. 215-216). Uma das formas de se obter essa autenticação era por meio da exposição do que o ancestral de um indivíduo fez ou quem ele era, em contraste com o ancestral de outro, e especialmente o exercício de altas magistraturas ou a obtenção de triunfos militares eram feitos que agregavam importância a uma gens. ${ }^{2}$ Em sua análise sobre a cultura política da aristocracia romana, Karl-Joachim Hölkeskamp (2010) destaca que, não apenas realizações concretas e méritos pessoais contavam como um critério legítimo de progresso para as altas magistraturas, mas também a reputação familiar, que funcionava como uma espécie de "recomendação", "pagamento antecipado" ou "crédito". Remetendo-se a Pierre Bourdieu, Hölkeskamp considera essa recomendação familiar o "capital simbólico" da aristocracia romana, uma cuidadosa coleção e arquivamento de honras ancestrais equivalente à herança particular de uma família, continuamente acumulada e acessada por intermédio da posse de um nome gentílico (HÖLKESKAMP, 2010, p. 107-108).

Diante do exposto, o presente artigo tem como proposta analisar as imagens monetárias de dois denários cunhados em Roma no ano de 137 AEC (RRC 234/1; 235/1), com o objetivo de refletir sobre como essas cunhagens se inserem no debate que ocupou grande parte da elite romana naquele ano, a respeito da ratificação ou não de um tratado feito pelo general Caio Hostílio Mancino após um insucesso militar diante da cidade de Numância. ${ }^{3}$ Foi elaborado a partir dos resultados obtidos com a pesquisa desenvolvida junto ao Programa de Pós-Graduação em História da Universidade Federal do Estado

\footnotetext{
${ }^{2}$ Uma gens compreendia todos os descendentes livres legítimos do sexo masculino de um ancestral comum, ainda que muito distante ou, algumas vezes, estabelecido a partir de uma genealogia forjada que, assim, tomavam o mesmo nomem (HÖLKESKAMP, 2004, p. 118; SMITH, 2006, p. 31). O nomen é o segundo nome dos romanos, depois do praenomen e antes do cognomen, sendo que este último nem todos usavam. O praenomen, primeiro nome, não era distintivo. Havia poucos nomes próprios romanos disponíveis para os indivíduos do sexo masculino e as mulheres não tinham praenomina. O cognomen entra em uso principalmente a partir da República média, particularmente entre a elite. Alguns eram derivados de apelidos que se referiam a qualidades pessoais, outros eram adjetivos enaltecedores e outros ainda tinham origem obscura. Assim, a identidade de um romano era demonstrada principalmente pelo seu nome do meio, que indicava a gens a que pertencia, e era a chave que acessava toda a herança familiar, da qual o indivíduo era possuidor (HÖLKESKAMP, 2004, p. 119; HÖLKESKAMP, 2014, p. 69).

${ }^{3}$ A indicação do ano de 137 AEC como sendo o da cunhagem das moedas segue a datação de Michael Crawford no catálogo Roman Republican Coinage (RRC, 1974) e será aqui acatada por ser tradicionalmente a mais aceita pela numismática romana. Mais recentemente, contudo, José Ignácio San Vicente (2012, p. 322), ao estudar o episódio de Mancino, ponderou que, uma vez que as imagens monetárias se referem ao tratado com Numância, não haveria condições materiais para que as emissões tivessem acontecido em 137 AEC, sendo 136 AEC o ano mais provável para as cunhagens. Ainda sobre as moedas, no Brasil, há dois exemplares do denário de Sexto Pompeu na coleção de moedas romanas da Universidade de São Paulo (USP) (FLORENZANO; RIBEIRO; LO MONACO, 2015, p. 29, n. 13, 14). O Museu Histórico Nacional do Rio de Janeiro (MHN-RJ) possui, em sua coleção de numismática, três exemplares do denário de Tibério Vetúrio e quatro exemplares do denário de Sexto Pompeu (MAGALHÃES, 2016, p. 53-54, n. 252 a 258).
} 
do Rio de Janeiro (UNIRIO) durante a elaboração de minha tese de doutorado (AYRES, 2017). Dentro da característica da aristocracia romana, de buscar nos antepassados a validação de suas ações, será dada especial ênfase à forma como as ações ancestrais são evocados pelo discurso numismático. Outro aspecto a ser destacado diz respeito à presença e participação dos deuses na elaboração das mensagens veiculadas pelas moedas, uma demonstração da impossibilidade de separar política e religião quando se trata da vida pública romana do período. Tentarei ainda demonstrar que, nas moedas do final do século II AEC, as referências numismáticas às ações no campo de batalha não podem ser resumidas a tentativas de registrar grandes vitórias ou feitos destacados com intenções laudatórias, ainda que isso também tenha acontecido de forma frequente. As duas peças em questão foram emitidas após uma derrota romana no campo de batalha, que gerou um impasse institucional e foi principalmente essa situação que forneceu as principais linhas dos discursos veiculados pelas peças.

\section{Mancino e a campanha contra Numância}

A trajetória de Caio Hostílio Mancino e seu trágico fim são um episódio relativamente bem conhecido dentro da história da República romana. Eleito um dos cônsules para o ano de 137 AEC, ao lado de M. Emílio Lépido Porcino (BROUGHTON, 1951, p. 484), Mancino dirigiu-se, junto com seu questor Tibério Semprônio Graco, para a Hispânia a fim de comandar as forças romanas na região. Efetuou várias ações militares contra a cidade de Numância, mas seu exército acabou cercado pelas forças numantinas, provavelmente em agosto daquele ano (Apiano, Hispania, 80). Desenvolveram-se negociações, nas quais o questor teve papel decisivo. Tibério Graco possuía prestígio na região por ser filho do propretor do mesmo nome que, no ano de $179 \mathrm{AEC}$, havia firmado uma série de pactos com os cetílberos, que haviam permanecido vigentes até o início do conflito em curso. Depois de estabelecido um acordo em termos de igualdade e dos juramentos que comprometiam Mancino e seus oficiais, o exército romano retirou-se desarmado (Floro, Epitome, 1, 34). O tratado, porém, teria que ser confirmado pelo Senado e pelo populus romanus e a decisão de Mancino foi alvo de severas críticas por parte do povo e dos senadores igualmente. Após um intenso debate, o tratado foi rechaçado e Mancino entregue aos numantinos.

O modelo segundo o qual um general derrotado era punido em seu retorno era muito raro na República romana. Muitos generais batidos em combate não eram processados quando voltavam e uma substancial proporção desses alcançava altas magistraturas, até novos comandos militares. Apenas contra uma minoria a punição era 
tentada e não em todos os casos era aplicada com sucesso (ROSENSTEIN, 1986, p. 230231). Um dos aspectos que explicam o fato era o pressuposto de que, ainda que as atuações humanas não fossem irrelevantes em um combate, o essencial era o apoio divino, sem o qual não havia como vencer. Como os deuses eram superiores e infinitamente mais poderosos do que os homens, mesmo que os erros de um general pudessem contribuir para a perda de uma batalha, isso poderia ser obscurecido pela falta de apoio divino em uma empreitada. A justificativa, contudo, teria que ser usada com cautela, pois a mesma aristocracia que fornecia os magistrados também fornecia aqueles que conduziam o culto público; então, um fracasso podia colocar em dúvida a habilidade de todo o sistema de assegurar a boa relação com os deuses. Além da boa vontade dos deuses e da capacidade de liderança dos generais, o desempenho do exército e a disciplina dos soldados também eram essenciais para as vitórias militares (ROSENSTEIN, 1990, p. 55; p. 92). Assim, generais dividiam a responsabilidade de uma derrota com os deuses e com os soldados. Como Roma vencia mais do que perdia, para a aristocracia dirigente era mais vantajoso absorver eventuais insucessos do que expor publicamente o general vencido e colocar em risco toda a sua capacidade de administrar a República, pois "toda vitória (ou derrota) era uma ação conjunta envolvendo a cidade e o campo de batalha" (ROSENSTEIN, 1990, p. 112).

No caso de Mancino, contudo, esse padrão não se repetiu. Para Nathan Rosenstein (1986, p. 235-236; 1990, p. 136-137), os detalhes do pacto não eram o ponto central. A grande questão era a forma como se dera a rendição de Mancino, percebida como desonrosa, e nem as vantagens diplomáticas nem as vidas dos homens que foram poupadas compensavam a humilhação que ela representou. A honra era um aspecto fundamental na transição da derrota para a punição. Esperava-se que Mancino tivesse tido a coragem de abrir caminho diante do cerco inimigo, ainda que pagando o preço de ter seu exército inteiro aniquilado. Segundo José Ignácio San Vicente (2013), a posição do Senado, reticente ao acordo de Mancino, deveu-se, basicamente, a questões políticas. Em sua defesa, Mancino e seus oficiais haviam acusado Quinto Pompeu, que comandara as forças romanas contra Numância antes dele, de ter rompido a pax deorum, por violar um pacto de 139 AEC, o que teria causado as sucessivas derrotas subsequentes dos romanos na região (App., Hisp., 80; Cícero, De Officiis, 3, 109). ${ }^{4} \mathrm{~A}$ defesa se fundamentava na alegação de que o tratado havia sido inevitável por duas razões. Primeiro, as tropas que Mancino recebera de seu predecessor eram preguiçosas e indisciplinadas; segundo,

\footnotetext{
${ }^{4} \mathrm{~A}$ noção de pax deorum deve ter existido desde a época arcaica, uma vez que todo ritual romano tinha por finalidade conservar a boa relação com os deuses. A partir de certo momento, esses rituais se tornaram um culto público oficial da República, cuja finalidade era prevenir a ruptura e apaziguar os possíveis temores da comunidade em relação a um possível abandono dos deuses (SAN VICENTE, 2013, p. 178).
} 
Pompeu havia também sofrido derrotas e sido forçado a negociar um tratado com os numantinos, que os romanos haviam inapropriadamente ignorado. Como resultado, a guerra que Mancino herdara havia sido renovada de uma forma inadequada. Acatar essa posição e abrir caminho para a ratificação do pacto de Mancino equivaleria a reconhecer que se estava levando a cabo uma guerra não justa, conduzindo o Senado (e o segmento do poder dentro da República que ele representava) a assumir um erro anterior na condução da questão (SAN VICENTE, 2013, p. 178-185).

No mesmo ano de 137 AEC, enquanto estava em curso o debate acerca da ratificação ou não do tratado de Mancino, Tibério Vetúrio e Sexto Pompeu, dois dos monetários daquele ano, cunharam seus denários (Figura 1 e Figura 2). As peças seguem um padrão iconográfico comum para o tipo no período, a efígie de uma divindade no anverso e uma cena de corpo inteiro no reverso. As imagens monetárias do reverso, porém, rompem com a tradicional presença dos Dióscuros ou de divindades guiando carros em movimento, recorrentes nas cunhagens até então (CRAWFORD, 1974, p. 266).

Tibério Vetúrio era filho de T. Vetúrio Graco F. Semproniano, áugure em 174 AEC, e a grafia do nome de seu pai indica um Graco adotado por um T. Vetúrio (RÜPKE, 2008, p. 951). Ou seja, o monetário tinha ligações familiares com o questor de Mancino. Por outro lado, Sexto Pompeu guardava parentesco com o cônsul Quinto Pompeu, que havia firmado o primeiro tratado com os numantinos e que, naquele momento, se opunha à ratificação do acordo de Mancino (CRAWFORD, 1974, p. 234; SAN VICENTE, 2012, p. 322-323). Assim, figuras atuantes na vida pública romana do período, esses monetários utilizaram os "espaços portáteis" (CLARK, 2007, p. 139) representados pelas moedas que cunharam para evocar o passado, posicionar acerca do presente e estabelecer projeções sobre o futuro, conforme pretendo demonstrar a seguir.

Figura 1 - Denário de Tibério Vetúrio

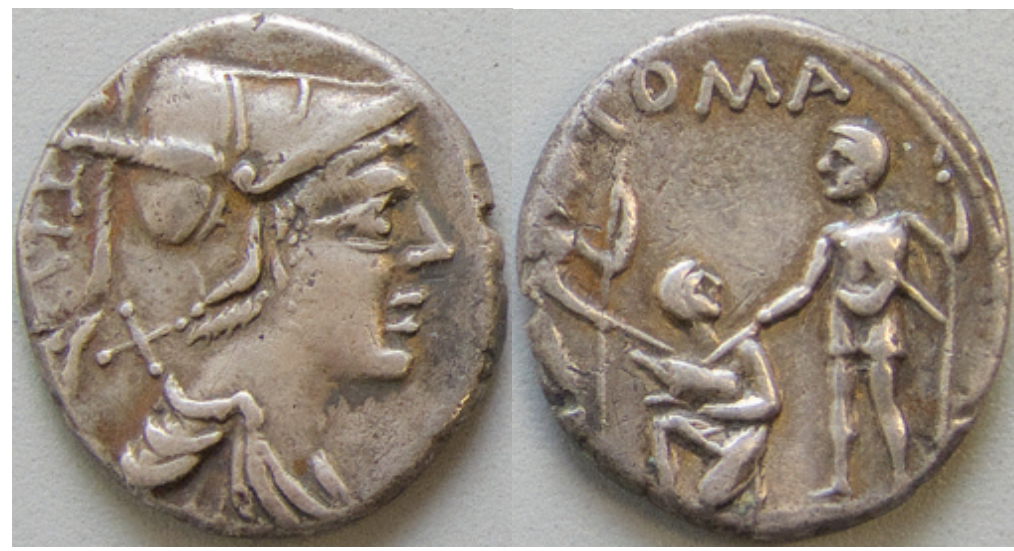

Fonte: Yale Art Gallery (2001, 87, 736), domínio público. 
Figura 2 - Denário de Sexto Pompeu

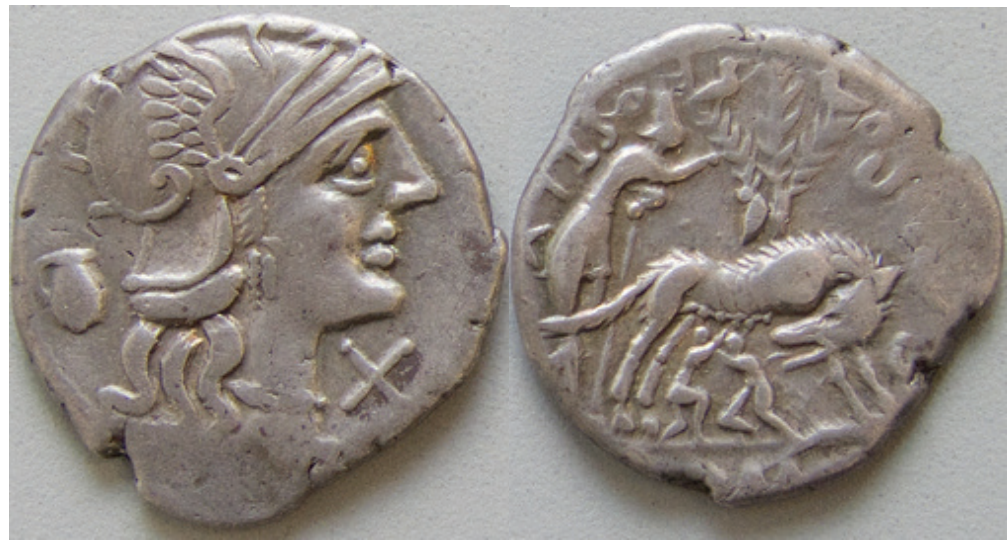

Fonte: Yale Art Gallery (2001, 87, 651), domínio público.

\section{Deuses e antepassados na moeda de Tibério Vetúrio}

Na ocasião da cunhagem dos denários aqui analisados, a deusa Roma, divindade feminina com atributos guerreiros que personificava a cidade republicana, predominava largamente nos anversos, aparecendo, por exemplo, em vinte e sete dos vinte e oito denários conhecidos cunhados da década de 130 AEC (CRAWFORD, 1974, p. 263-282). Na peça de Tibério Vetúrio (Fig. 1), a única exceção, o anverso é ocupado pela efígie de Marte, o deus romano da guerra. Atrás da imagem está a legenda identificando o monetário, TI VET (em monograma), e, entre o penacho do elmo e o pescoço do deus, a marca de valor do denário $(X)$. Além do pai dos gêmeos fundadores, Marte era uma divindade prestigiada em uma cidade conquistadora como Roma. Ainda assim, é pouco provável que sua escolha pelo monetário para ocupar o anverso da moeda tenha sido casual. Uma possibilidade seria a tentativa de Tibério Vetúrio de evocar uma relação entre ele próprio e sua gens com o lendário ferreiro Vetúrio Mamúrio. Após Numa Pompílio - o segundo rei de Roma, a quem a tradição atribui a criação das instituições religiosas romanas - ter estabelecido o pacto da cidade com o divino, um escudo teria caído do céu, um presente dos deuses após o fim de uma praga. Para prevenir o furto do escudo, símbolo que era da aliança entre deuses e homens, Numa encomendou a confecção de onze cópias, exatamente iguais, de modo a confundir quem porventura tivesse a intenção de roubá-lo. O encarregado da tarefa, Vetúrio Mamúrio, desempenhou tão bem o trabalho que, ao final, nem o próprio Numa conseguia identificar o verdadeiro escudo (Plutarco, Num., 23). O rei escolheu ainda os doze sacerdotes sálios, em honra ao deus Marte, e ordenou-lhes que usassem os escudos caídos do céu, os ancilia, e saíssem pela cidade cantando hinos acompanhados de saltos ritmados e danças (Lívio, 
Ab Urbe condita, 1, 20). É possível que a presença de Marte em forma de efígie no anverso da moeda evoque o episódio, apelando para uma possível descendência de seu idealizador em relação ao ferreiro habilidoso e mítico.

Na cena do reverso do denário de Tibério Vetúrio (Figura 1), dois soldados seguram lanças com a mão esquerda e empunham espadas com a mão direita. As espadas apontam na direção de uma terceira figura, ajoelhada entre ambos, que segura um porco. Ao alto, a legenda ROMA, indicando a origem da cunhagem. Interpretada como a representação de um juramento, a iconografia reproduz uma emblemática cunhagem de ouro realizada pelos romanos no curso do século III AEC, o "ouro do juramento". Tradicionalmente situada entre os anos de 225 e 212 AEC, a emissão do "ouro do juramento" teve recentemente sua cronologia delimitada de forma mais precisa por Filippo Coarelli, que a situou nos anos de 219 ou 218 AEC (RRC 28/1; CRAWFORD, 1974, p. 25; FLORENZANO, 2015, p. 16; COARELLI, 2013, p. 83-90). A datação de Coarelli parte de interpretações alternativas para algumas questões tradicionalmente aceitas pela numismática republicana, entre elas a associação do início de uma cunhagem genuinamente romana ao período e às demandas trazidas pela Segunda Guerra Púnica. Coarelli situa esse início em um momento anterior, fixando os primórdios das amoedações romanas em prata por ocasião das guerras contra Pirro e Tarento, cujo butim teria servido para cunhar, em 269 AEC (COARELLI, 2013, p. 83-90; ESQUIVEL, 2014, p. 231). Seguindo essa perspectiva, o primeiro tipo romano cunhado em prata teria sido o quadrigato, nome derivado da quadriga que constituía a cena padrão do reverso. Na sequência, teria sido cunhado o "ouro do juramento", segundo Plínio, cinquenta e um anos depois das cunhagens em prata (Plínio, Naturalis Historia, 33, 47). Coarelli acata informações de Plínio rejeitadas por trabalhos tradicionais (CRAWFORD, 1974; BURNETT, 1986) e acredita ainda que o responsável pela cunhagem tenha sido Vetúrio Filo, conquistador, no ano de 220 AEC, da região da Gália Cisalpina, onde se localizavam minas de ouro (BROUGHTON, 1951, p. 235). O fato de o denário de Tibério Vetúrio, quase um século depois, recorrer à mesma iconografia, se explica, segundo Coarelli (2013, p. 100), por um parentesco entre os dois Vetúrios.

O juramento representado nas peças segue o estilo dos povos itálicos, tendo sido interpretado, às vezes, como o pacto entre Roma e seus aliados da Península (SEABY, 1967, p. 96; SAN VICENTE, 2012, p. 322; RRC 234/1; CRAWFORD, 1974, p. 715). Uma parte importante do episódio de Mancino foi o juramento feito ao final da celebração do acordo. $\mathrm{O}$ acontecimento é assim narrado por Apiano:

Mancino teve encontros frequentes com os numantinos, nos quais foi vencido e, finalmente, depois de grandes perdas, se refugiou em seu campo. Diante do falso rumor que os Cantabri e os Vaccaei estavam vindo para ajudar os numantinos, 
ficou alarmado, levantou acampamento e fugiu, na escuridão da noite, para um local deserto onde Nobilior, uma vez, tivera um campo. Sendo contido neste lugar ao amanhecer, sem preparação ou fortificação e cercado pelos numantinos que ameaçavam todos com a morte caso não concordassem com a paz, ele concordou com termos como os anteriormente feitos entre romanos e numantinos. A esse acordo, ele se comprometeu com um juramento (App., Hisp., 80)

As referências itálicas e a alusão a juramentos levam ainda à associação da cena a um acontecimento da história romana ocorrido cerca de cento e oitenta anos antes, durante a Segunda Guerra Samnita, o episódio das Forcas Caudinas de 321 AEC. Ainda mais porque um dos cônsules derrotados na ocasião era também um Vetúrio, T. Vetúrio Calvino (Liv., Ab urb. cond., 9, 1; BROUGHTON, 1951, p. 150). Os romanos foram emboscados pelos samnitas entre dois desfiladeiros e não tiveram alternativas a não ser negociar uma rendição em termos altamente desfavoráveis. Embora considerando o acordo humilhante, Roma, após alguma resistência, honrou o estabelecido (Liv., $A b$ urb. cond., 9, 2-11). Entendo ser pertinente a hipótese de que a moeda, ao resgatar esse evento do passado (RRC 234/1; SAN VICENTE, 2012, p. 322-325), propunha sua resposta a uma discussão do presente: um acordo de guerra, ainda que desfavorável, devia ser cumprido. Seu idealizador possivelmente se posicionava favoravelmente ao cumprimento do tratado de Mancino e uma das explicações para tal era provavelmente o parentesco do pai do monetário com o questor Tibério Graco, conforme citei acima. Considero que essa interpretação é reforçada pela presença inusitada de Marte no anverso do denário, em um momento em que esse espaço era claramente dominado pela presença da deusa Roma. No discurso numismático romano republicano, seres divinos e símbolos religiosos ajudam a narrar as ações humanas e os acontecimentos que envolviam a cidade. A presença do deus, cujos sacerdotes sálios empunhavam o escudo símbolo da aliança com o divino, evoca os preceitos que regem a condução de uma guerra que conta com a aprovação dos deuses. A posse do precioso escudo e a manutenção da aliança que ele representava fora assegurada no passado com o auxílio de um Titúrio, o ferreiro encarregado da fabricação das cópias. Nada excepcional que agora outro Titúrio se encarregasse de relembrar aos romanos a importância da guerra conduzida de forma justa.

\section{O destino imperial de Roma no denário de Sexto Pompeu}

Em contrapartida, há o denário de Sexto Pompeu (Fig. 2), cunhado no mesmo ano. No anverso, a efígie da deusa Roma, conforme já citado. A marca de valor $(X)$ está embaixo do queixo da deusa e à esquerda a representação de um jarro. Embora o jarro esteja entre os objetos rituais mais frequentemente representados nas cenas de sacrifício 
na arte romana, juntamente com a patera (prato para o sacrifício) e a acerra (caixa de incensos), além de um altar ou uma mensa (mesa) (MÖEDE, 2007, p. 165; STEWART, 1997, p. 171-173), sua presença não é frequente nas cunhagens monetárias do século II AEC. Assim, sua interpretação é, em geral, reduzida às peças produzidas na República tardia, a partir das cunhagens de Sila, associado ao lituus (bastão de extremidade curva que os sacerdotes áugures portavam). Observando-o isoladamente, a conexão mais imediata que se estabelece é com o contexto dos sacrifícios. Na moeda de Sexto Pompeu, relacionando o jarro do anverso com a cena do reverso, Michael Crawford acredita que seja uma alusão ao culto à Rumina, divindade tida como protetora das crianças (Plut., Rom., 5; RRC 235/1ac; SMITH, 1870, v. 3, p. 679). Não há outros elementos que corroborem ou contradigam essa hipótese, porém certamente a representação não é aleatória, pois o jarro também aparece em um semis de bronze cunhado no mesmo ano pelo monetário (RRC 235/2).

O reverso traz Rômulo e Remo sendo amamentados pela loba, árvore (fícus Ruminalis) atrás com um pássaro pousado e dois pássaros sobrevoando, pastor Faustulus identificado pela legenda FOSTLVS à esquerda e ROMA no exergo. O momento da cunhagem é o de florescimento dos novos tipos na numismática romana, com recorrentes apelos aos antepassados dos monetários, mas não há registros de uma tradição que associe Sexto Pompeu (ou algum ramo da gens Pompeia) ao pastor responsável pelo resgate dos gêmeos fundadores. Em seu dicionário de biografia e mitologia, William Smith (1870, v. 3, p. 473) aponta Faustulo ou Fausto como um cognome da gens Pompeia, mas essa informação se baseia exatamente na existência da moeda de 137 AEC, não podendo ser corroborada por outras fontes. Por outro lado, uma vez que a fundação de Roma era um acontecimento importante demais para ser evocado por uma única família, concordo com a interpretação segundo a qual, a imagem monetária, ao relembrar a origem mítica e grandiosa da cidade, evoca seu destino conquistador estabelecido desde seu surgimento, o qual deveria prevalecer (RRC 235; SAN VICENTE, 2012, p. 322-323). À cidade triunfante, personificada pela deusa com atributos guerreiros do anverso, não cabia compactuar com condutas desonrosas no campo de batalha nem se submeter a acordos humilhantes. Marte, o deus da guerra, não é figura totalmente alheia à cena, pois ele é, segundo a tradição, o pai de Rômulo e Remo. Mas, sua figura se encontra, de certa forma, obscurecida pela cena e o que ela representa: o grandioso nascimento de Roma.

É verdade, porém, que, neste caso, as evidências da relação da cunhagem com o episódio de Numância são menos claras do que na moeda anterior. Na peça de Vetúrio, a existência de antepassados do monetário envolvidos com o momento da cunhagem do "ouro do juramento" (cuja iconografia emblemática a peça reproduz) e com o episódio das Forcas Caudinas tornam as referências para a escolha do monetário mais consistentes. 
No denário de Sexto Pompeu, o ineditismo da posição contrária à ratificação do acordo de Mancino torna essa busca por correspondências mais difícil. Como lembra San Vicente (2013, p. 183), Mancino, investido com uma magistratura cum imperium militare, podia tomar os auspícios, realizar as cerimônias e pronunciar as fórmulas religiosas de um tratado. Ou seja, tinha condições, como cônsul, de realizar um pacto em nome de Roma, embora esse devesse ser sancionado pelo Senado e pelo povo de Roma. Com toda certeza, o acordo era desvantajoso para os romanos em termos políticos, estratégicos e, possivelmente, econômicos, mas isso, por si só, não era razão para recusar sua ratificação. O ineditismo da reação articulada principalmente pelo Senado carecia de exemplos na conduta dos antepassados. Restava, então, apelar para a grandiosidade da cidade de Roma, cuja manutenção as decisões deveriam visar. Não por acaso, referências à urbs ocupam os dois lados da moeda, por meio da deusa que a simboliza e por intermédio da cena que evoca sua origem incomum.

\section{Considerações finais}

Ao pensarmos como a iconografia numismática republicana lida com o aspecto militar que compunha o capital simbólico da aristocracia romana, aquele ligado ao desempenho dos ancestrais em guerras, batalhas ou duelos, o esquema padrão que em geral vem à mente é o de uma grande vitória pretérita monumentalizada em uma moeda. Isso pode ser verdadeiro na maior parte dos casos, mas não o é em todos os casos. As moedas de Tibério Vetúrio e Sexto Pompeu são exemplos da quebra desse paradigma e demonstram um pouco da complexidade do discurso numismático republicano romano do século II AEC. O que estava em pauta no discurso veiculado por intermédio dessas duas cunhagens não era uma vitória e sim uma derrota (no campo de batalha, que provocara uma derrota diplomática) e o posicionamento diante dela. No caso da moeda de Tibério Vetúrio, o mérito dos antepassados estava justamente em saber como se comportar diante de um fracasso bélico, de acordo com as normas tradicionais que regiam a feitura da guerra e o estabelecimento da paz no mundo romano, e esse era o capital simbólico que os Titúrios procuravam resgatar. A resposta que a moeda propõe é que se sigam os preceitos estabelecidos pela tradição. Não por acaso, neste denário, e apenas neste dentre todas as peças do mesmo tipo produzidas na década de 130 AEC, Marte "toma" o lugar de Roma como a divindade cuja efígie ocupa o anverso. Mais do que os interesses momentâneos da cidade-Estado republicana, da qual a deusa é a mais perfeita personificação, há de se considerar os princípios que regem a guerra, da qual Marte é o maior representante. Dentre esses princípios, estava a necessidade de uma 
guerra justa, para que não se despertasse o descontentamento dos deuses e se corresse o risco de rompimento da pax deorum. No caso do denário de Sexto Pompeu, a efígie da deusa Roma e a lembrança do espetacular resgate dos gêmeos fundadores sugerem outra resposta à mesma questão: a inclinação à vitória e ao triunfo sobre os outros povos acompanhou Roma desde seu surgimento e assim deveria continuar. Quando se consegue ir além da camada de símbolos aparentes da grandiosidade da cidade de Roma registrados nas peças (deuses, mitos e relatos enaltecedores sobre o passado), e principalmente quando lemos as duas moedas em conjunto, o que está por trás de suas iconografias é um grande desconforto diante de uma derrota e a incerteza e o conflito gerados pela discussão de como prosseguir diante disso.

As peças são também exemplos da riqueza e variedade da iconografia numismática republicana na segunda metade do século II AEC e de sua afinidade com seu contexto de produção, convidando os pesquisadores a um olhar mais cuidadoso sobre as imagens monetárias do período anterior aos conflitos que antecederam o final da República Romana. Em termos republicanos, estudos dessa natureza têm, em geral, se concentrado, cronologicamente, nas cunhagens produzidas a partir das agitações da segunda metade do século I AEC, por iniciativa daqueles que aspiravam ao poder pessoal. Podemos afirmar hoje, porém, que símbolos religiosos em moedas, na elaboração de mensagens que versavam sobre política e poder, não foram uma prerrogativa inaugurada pelos generais dos últimos tempos da República, mas sim utilizados pelos homens públicos que os antecederam, ainda durante o funcionamento regular das instituições republicanas, um fenômeno que utilizou recursos discursivos diversos e partiu da iniciativa de emissores variados. A incipiência de estudos dessa natureza e a diversidade do discurso numismático do período tornam o campo promissor para o desenvolvimento de novas e inéditas pesquisas.

\section{Referências}

\section{Documentação textual}

APPIAN. The Spanish wars. London: Heinemann, 1913.

CICERO. De officiis. Cambridge: Harvard University Press, 1913.

FLORUS. Epitome of Roman History. Cambridge: Harvard University Press, 1929.

PLINY THE ELDER. The Natural History. London: Taylor and Francis, 1855.

PLUTARCO. Numa Pompílio. In: PLUTARCO. A vida dos homens ilustres de Plutarco. São Paulo: Editora das Américas, 1951, p. 263-315. 
PLUTARCO. Rômulo. In: PLUTARCO. A vida dos homens ilustres de Plutarco. São Paulo: Editora das Américas, 1951, p. 111-177.

TITO LÍVIO. História de Roma. São Paulo: Paumape, 1989.

\section{Documentação numismática}

CRAWFORD, M. H. Roman republican coinage. Cambridge: Cambridge University Press, 1974. 2 v.

FLORENZANO, M. B. B.; RIBEIRO, A. M. G. R.; LO MONACO, V. A coleção de moedas romanas da Universidade de São Paulo: Museu Paulista e Museu de Arqueologia e Etnologia. São Paulo: MAE-USP, 2015.

MAGALHÃES, M. M. Sylloge nummorum romanorum Brasil l: moedas romanas republicanas. Rio de Janeiro: Museu Histórico Nacional, 2016.

SEABY, H. A. Roman silver coins: the Republic to Augustus. London: Seaby, 1967. v. 1.

SEAR, D. R. Roman coins and their values: the Republic and the Twelve Caesars. London: Spink and Son Ltd, 2000. v. 1.

\section{Obras de apoio}

AYRES, G. O. B. Quando o divino celebra o humano: religião, política e poder nas moedas republicanas romanas (139-83 AEC). Tese (Doutorado em História) - Programa de Pós-Graduação em História da Universidade Federal do Estado do Rio de Janeiro, Rio de Janeiro, 2017.

BROUGHTON, T. R. S. The magistrates of the Roman Republic (509 BC-100 BC.). New York: American Philological Association, 1951. v. 1.

BROUGHTON, T. R. S. The magistrates of the Roman Republic (99BC-31BC). New York: American Philological Association, 1952. v. 2.

BURNETT, A. Coinage in the Roman world. London: Spink and Son, 1986.

CLARK, A. J. Divine qualities. New York: Oxford University Press, 2007.

COARELLI, F. Argentum signatum: le origini della moneta d'argento a Roma. Roma: Istituto Italiano di Numismatica, 2013.

ERNOUT, A.; MEILLET, A. Dictionnaire étymologyque de la langue latine. Paris: Klincksieck, 2001.

ESQUIVEL, A. M. Recensión de COARELLI, Filippo. Argentum Signatum. Le origini della moneta d'argento a Roma. Zephyrus, n. 74, p. 231-234, 2014. 
HÖLKESKAMP, K.-J. In defense of concepts, categories and other abstractions: remarks on a theory of memory (in the making). In: GALINSKY, K. (Ed.). Memoria romana: memory in Rome, Rome in memory. Ann Arbor: The University of Michigan Press, 2014, p. 63-70.

HÖLKESKAMP, K.-J. Reconstructing the Roman Republic: an ancient political culture and modern research. Princeton: Princeton University Press, 2010.

HÖLKESKAMP, K.-J. Under Roman roofs: family, house and household. In: FLOWER, H. I. (Ed.). The Cambridge Companion to the Roman Republic. Cambridge: Cambridge University Press, 2004, p. 113-138.

MEADOWS, A.; WILLIAMS, J. Moneta and the monuments: coinage and politics in Republican Rome. The Journal of Roman Studies, v. 91, p. 27-49, 2001.

MOEDE, K. Reliefs, public and private. In: RÜPKE, J. (Ed.). A Companion to Roman religion. London: Blackwell, 2007, p. 164-175.

MORSTEIN-MARX, R. Mass oratory and political power in the late Roman Republic. Cambridge: Cambridge University Press, 2004.

ROSENSTEIN, N. Imperatores victi: military defeat and aristocratic competition in the Middle and Late Republic. Berkeley: University of California Press, 1990.

ROSENSTEIN, N. Imperatores victi: the case of C. Hostilius Mancinus. Classical Antiquity, v. 5, n. 2, p. 230- 252, 1986.

RÜPKE, J. Fasti sacerdotum: prosopography of pagan, Jewish and Christian religious officials in the city of Rome (300 BC to AD 499). Oxford and New York: Oxford University Press, 2008.

SAN VICENTE, J. I. La victoria como justificación del bellum pium y la pax deorum: el caso de Numancia. Arys, n. 11, p. 173-192, 2013.

SAN VICENTE, J. I. El foedus de Mancino, la Pax Caudina y Tito Livio. In: MARTíNEZ, J. (Ed.). Mundus vult decipi: estúdios interdisciplinares sobre falsificación textual y literaria. Madrid: Clásicas, 2012, p. 319-334.

SMITH, C. J. The Roman clan: the gens from ancient ideology to modern Anthrophology. Cambridge: Cambridge University Press, 2006.

SMITH, W. Dictionary of Greek and Roman biography and mithology. Boston: Litle, Brown and Company, 1870. 3 v.

STEWART, R. The jug and lituus on Roman Republican coin types: ritual symbols and political power. Phoenix, v. 51, n. 2, p. 170-189, 1997.

SUSPÈNE, A. Sur la loi monétaire de c. 212 (?). Cahiers Glotz, n. 13, p. 33-43, 2002.

WALLACE-HADRILL, A. Rome's cultural revolution. Cambridge: Cambridge University Press, 2009. 
WELCH, K. E. Art and architecture in Republican Rome. In: ROSENSTEIN, N.; MORSTEINMARX, R. (Ed.). A Companion to the Roman Republic. London: Blackwell, 2006, p. 496-542.

WISEMAN, T. P. New men in the Roman Senate. 139 B.C. 14 A.D. Oxford: Oxford University Press, 1971. 